\title{
Projeto de extensão universitária de apoio escolar às crianças com dificuldades de aprendizagem: integração de saberes e prestação de serviço
}

\author{
Sônia Aparecida Belletti Cruz ${ }^{1}$
}

\begin{abstract}
RESUMO
Estudos apontam a importância da formação inicial de qualidade para formar docentes reflexivos e questionadores sobre os problemas cotidianos e os fundamentos científicos. Embasado nas concepções de Meirieu (1998, 2002 e 2006) sobre conhecimentos docentes, o presente trabalho objetiva relatar experiências de universitários do curso de Pedagogia da UNIP-Araraquara-SP, no desenvolvimento do projeto de extensão de apoio escolar às crianças com dificuldades de aprendizagem do Ensino Fundamental, visando a integrar saberes e prestação de serviço. Pioneiro no curso de Pedagogia, tal projeto se utiliza de recursos pedagógicos diversificados e diferenciados e as propostas de atividades são cuidadosamente planejadas, já que devem se adequar ao nível de desenvolvimento da criança. Analisando os trabalhos desenvolvidos, pode-se considerar que quando as crianças vivenciam atividades prazerosas e desafiadoras, e que dão vontade de aprender, sem dúvida sua reação é positiva frente à intervenção que recebem.
\end{abstract}

Palavras-chave: Formação de professores. Projeto de extensão. Dificuldade de aprendizagem.

\section{ABSTRACT}

Studies has shown the importance of a high quality basic formation in forming reflexive and questioning teachers about everyday problems and scientific foundations. Grounded in the concepts of Meirieu (1998, 2002 and 2006) on teaching knowledge, the present study reports college experiences from UNIPAraraquara-SP in the development of extension project in school support for children of Elementary School with learning difficulties, intending to integrate knowledge and social service. A pioneer in the Faculty of Education, this project makes use of diverse and differentiated learning resources and the proposed activities are carefully planned, since they must suit the child's developmental level. Analyzing the work done, it can be considered that when children experience enjoyable and challenging activities that give willingness to learn, no doubt their reaction is positive toward the intervention they receive. frente à intervenção que recebem.

Keywords: Teacher basic formation. Extension project. Learning difficulties.

\footnotetext{
1 Doutora em Educação Escolar pela UNESP de Araraquara-SP. Professora da rede estadual paulista e da UNIP de Araraquara-SP. E-mail: soniabelletti@yahoo.com.br
} 


\section{Introdução}

A constatação de número considerável de crianças que frequentam o banco escolar e não conseguem aprender a ler, a escrever ou a resolver problemas básicos de matemática tem trazido inquietude e questionamentos aos profissionais da educação, em especial aos estudiosos, que buscam respostas que levem à compreensão desses problemas e a formas de contribuir para reversão do quadro de insucesso dessas crianças.

Pesquisa realizada com oito professores do ciclo I do Ensino Fundamental aponta que para eles as dificuldades de aprendizagem dos alunos são decorrentes de fatores individuais, familiares, escolares e sociais e, ao acumular frequentes fracassos, os alunos manifestam baixa autoestima e resistência ou negação na realização das atividades. E, também, que as intervenções pedagógica e afetiva para auxiliar essas crianças na realização de suas atividades escolares são consideradas por eles recurso efetivo para promover a motivação para os estudos e a reversão do insucesso escolar (CRUZ, 2003).

Para Meirieu (2006, p. 19), o acompanhamento do aluno deve proporcionarlhe segurança, de modo a possibilitar a cada um "confrontar-se com um saber que o ultrapasse e, ao mesmo tempo, fornecer-lhe a ajuda necessária para se aproximar dele (...)". Acompanhar o aluno significa pegá-lo onde se encontra, não para deixá-lo ali, mas para ajudá-lo a avançar de maneira exigente e poder perceber que, progressivamente, vai encontrando prazer nas atividades que realiza.

É evidente que para intervir de maneira eficiente, além de ter conhecimento dos conteúdos de sua área, o docente precisa conhecer as metodologias adequadas para ensinar. Porém, em alguns momentos, há aqueles que não conseguem aplicar as propostas formuladas teoricamente e se veem em situação nas quais suas concepções e preceitos são colocados em xeque, o que lhes traz sentimento de desconforto e de culpa (CRUZ, 2011).

Neste caso, Meirieu (1998) exorta os professores a não desistir de pôr em prática suas propostas teóricas, considerando-as úteis à ação pedagógica, porque mesmo que o esperado não ocorra, de alguma forma, algo de importante acontece no ato educativo.

A respeito dos conhecimentos docentes, antes de o professor iniciar sua formação, ele já possui a sua a cultura de escola e, no seu percurso profissional, vai mudando e ampliando suas ideias, à medida que vai amadurecendo pessoal e profissionalmente.

Na visão de Meirieu (1998), para se tornar profissional da educação, o professor depende de boa formação interior, de solidez de valores e atitudes, mas também de boa formação profissional; não é um dom e sim resulta da boa aprendizagem e da experimentação constante no sentido de encontrar boas estratégias e da vontade de executar um bom trabalho. $\mathrm{O}$ bom educador vive a sua prática almejando sempre atingir os melhores resultados.

Assim, surgem questões sobre os saberes adquiridose percebidospelosuniversitários nos cursos de formação docente: eles dominam os conteúdos a serem trabalhados e a metodologia adequada para ensinar? Aprenderam a relacionar aspectos teóricos com a prática pedagógica? O que sabem a respeito das dificuldades de aprendizagem e das formas efetivas de intervenção para ajudar os alunos a sanar tais dificuldades?

Estudos em torno da formação docente são constantemente abordados por pesquisadores da área da Educação. Alguns articulam formação inicial e continuada e outros se voltam às questões teórico-metodológicas e à reflexão sobre a prática pedagógica, dentre variados enfoques. 
Na visão de Mello (2001, p. 156), é necessário que o professor que terminou o curso de Pedagogia demonstre qualificação e se sinta preparado para atuar na educação básica, já que "ninguém promove a aprendizagem de conteúdos que não domina nem a constituição de significados que não possui ou a autonomia que não teve oportunidade de construir".

Para que formem bons profissionais, os cursos de licenciatura devem apresentar qualidade e valorizar o seu papel no contexto de sala de aula. Devem formar docentes que pensem e questionem os problemas cotidianos e os fundamentos científicos.

Partindo de tais premissas e embasado nas concepções de Meirieu (1998, 2002 e 2005) sobre os conhecimentos docentes, o presente trabalho objetiva apresentar as experiências vivenciadas por universitários do curso de Pedagogia da Universidade Paulista-Araraquara-SP e alunos dos $4^{\circ}$ e $5^{\circ}$ anos do Ensino Fundamental de três escolas públicas, também deste município, no desenvolvimento do projeto de extensão de apoio escolar às crianças com dificuldade de aprendizagem, que visa a integrar saberes e prestação de serviço.

\section{Diretrizes Curriculares Nacionais para o curso de Pedagogia em licenciatura (Resolução CNE/CP n 1/2006)}

Essa resolução define "princípios, condições de ensino e de aprendizagem, procedimentos a serem observados em seu planejamento e avaliação, pelos órgãos dos sistemas de ensino e pelas instituições de educação superior do país, nos termos explicitados nos Pareceres CNE/CP n ${ }^{\circ}$ 5/2005 e 3/2006" (Res. CNE/CP n $1 / 2006$, art. $1^{\circ}$ ).

O objetivo é a formação global dos pedagogos para que, além dos conhecimentos diretamente relacionados à profissão, possam trazer o que é esperado desse profissional para sua prática, ou seja, relacionar a vida na escola com a vida fora dela.

$\mathrm{O}$ artigo $3^{\circ}$ abrange a pluralidade de conhecimentos teóricos e práticos, que consolida o exercício da profissão:

\footnotetext{
Parágrafo único. Para a formação do licenciado em Pedagogia é central: I - o conhecimento da escola como organização complexa que tem a função de promover a educação para e na cidadania;

II - a pesquisa, a análise e a aplicação dos resultados de investigações de interesse da área educacional;

III - a participação na gestão de processos educativos e na organização e funcionamento de sistemas e instituições de ensino.
}

Tal formação traz novos horizontes à profissão do pedagogo que, em formação integrada, poderá atuar na docência, na gestão e na avaliação de sistemas e instituições de ensino, na elaboração, na execução e no acompanhamento de programas e das atividades educativas (Parecer CNE/CP n ${ }^{\circ}$ 05/2005).

Essa perspectiva se expressa, também, nos artigos $4^{\circ}$ e $5^{\circ}$ da Resolução CNE/CP n ${ }^{\circ}$ 01/2006, os quais definem a finalidade do curso de Pedagogia e as aptidões requeridas do profissional desse curso, assegurando a articulação entre a docência, a gestão educacional e a produção do conhecimento na área da Educação: 
No primeiro eixo, a Docência é considerada ponto central do processo formativo da licenciatura em Pedagogia, sua ação é exercida na Educação Infantil e nos anos iniciais do Ensino Fundamental, no Ensino Médio de modalidade Normal e nos cursos de Educação Profissional, caracterizando-se na área de serviços e apoio escolar, bem como em outras áreas nas quais sejam previstos conhecimentos pedagógicos. $\mathrm{O}$ trabalho pedagógico darse-á em espaços escolares e não escolares.

No segundo eixo, a Gestão compreende a atuação do pedagogo na gestão das instituições, planejando, executando, acompanhando e avaliando projetos e programas educacionais e em processos educativos, na organização e no funcionamento de sistemas e de instituições de ensino. Na escola, ao ter de tomar decisões na condução do processo educativo, o professor está exercendo a gestão do ensino, a gestão da classe, a gestão das relações, a gestão do processo de aquisição do conhecimento.

O terceiro e último eixo, que corresponde à Pesquisa e Produção do Conhecimento, dá-se por meio da participação em atividades de pesquisa, as quais propiciam ao licenciando o desenvolvimento de investigação científica. Tais práticas, presentes nos componentes curriculares, em seminários e em outras situações pedagógicas, objetivam o conhecimento de procedimentos de pesquisa e sua aplicação, bem como a interpretação de resultados de investigações e sua discussão teórica. Outra forma de pesquisa referese à investigação das especificidades da aprendizagem, as quais abordam as etapas de desenvolvimento nas quais se encontram as crianças, suas hipóteses de leitura e escrita, entre outras. Estudos demonstram que o desconhecimento dessas particularidades tem gerado aos professores a utilização de procedimentos impróprios e de intervenções inócuos, quando não desastrosos. Tal concepção de pesquisa se contrapõe à ideia de que somente no meio acadêmico é possível pensar, investigar e produzir conhecimento.

As DCNs apresentam no seu artigo $7^{\circ}$ a carga horária para o curso de Pedagogia, que deverá ser de, no mínimo, 3.200 horas de efetivo trabalho acadêmico. Está composta da seguinte forma:

I - 2.800 horas dedicadas às atividades formativas como assistência a aulas, realização de seminários, participação na realização de pesquisas, consultas a bibliotecas e centros de documentação, visitas a instituições educacionais e culturais, atividades práticas de diferente natureza, participação em grupos cooperativos de estudos;

II - 300 horas dedicadas ao Estágio Supervisionado prioritariamente em Educação Infantil e nos anos iniciais do Ensino Fundamental, contemplando também outras áreas específicas, se for o caso, conforme o projeto pedagógico da instituição;

III - 100 horas de atividades teórico-práticas de aprofundamento em áreas específicas de interesse dos alunos, por meio da iniciação científica, da extensão e da monitoria.

Assim, 2.800 horas deverão ocorrer em forma de aulas, visitas, palestras, seminários, apresentação de trabalhos, em companhia de professor orientador. Já 300 horas de estágio darão oportunidade de o universitário conhecer as instituições de Educação Infantil e dos anos iniciais do Ensino Fundamental e vivenciar seu contexto, acompanhando, observando e participando das atividades de sala de aula. Ainda, 100 horas desenvolvidas 
de atividades teórico-práticas são integradas às atividades complementares e fazem a ligação entre o mundo da cultura e da escola.

Nesse sentido, a partir desse novo olhar, a formação do pedagogo passa a exigir nova concepção de educação, de escola, da pedagogia, de docência e de licenciatura.

\title{
Formação inicial do pedagogo e extensão universitária
}

A formação inicial faz parte do desenvolvimento da profissionalização docente, processo este que se fundamenta em conhecimentos científicos e atividades práticas, na articulação entre teoria e prática, conforme aponta Imbernón (2006, p. 66):

\begin{abstract}
A formação inicial deve dotar de uma bagagem sólida nos âmbitos científico, cultural, contextual, psicopedagógico e pessoal, que deve capacitar o futuro professor ou professora a assumir a tarefa educativa em toda sua complexidade, atuando reflexivamente com a flexibilidade e o rigor necessários, isto é, apoiando suas ações em uma fundamentação válida para evitar cair no paradoxo de ensinar a não ensinar.
\end{abstract}

Neste sentido, o curso de Pedagogia deve ser um processo dinâmico de aprendizagem nas diferentes áreas de atuação no campo profissional, proporcionando aos universitários, futuros professores, embasamento teórico e metodológico que lhes permita aplicar os conhecimentos adquiridos e refletir sobre eles.

Em relação aos conhecimentos oferecidos pela universidade, sabe-se que a formação acadêmica baseia-se no tripé ensino, pesquisa e extensão. No ensino, transmitese de maneira sistemática o saber historicamente acumulado pela sociedade. A pesquisa é responsável pela geração de novos conhecimentos e desenvolvimento da tecnologia. Finalmente, a extensão incumbe-se de levar todo esse saber para fora da academia, servindo à comunidade e alimentando-se de novos desafios.

No que diz respeito à extensão universitária, sua finalidade é aproximar o conhecimento acadêmico com a realidade. Segundo Iamamoto (2000, p. 57) "a extensão é um processo educativo, cultural e científico que articula a universidade com as necessidades dos segmentos majoritários da população".

Segundo o Fórum de Pró-Reitores de Extensão das Universidades Públicas Brasileiras-Forproex (2012, p. 15), a extensão universitária denota uma postura da universidade na sociedade e "seu escopo é o de um processo interdisciplinar, educativo, cultural, científico e político, por meio do qual se promove uma interação que transforma não apenas a Universidade, mas também os setores sociais com os quais ela interage".

O conceito de Extensão definido pelo Forproex de 2001 salienta que: 


\begin{abstract}
A extensão universitária é o processo educativo que articula o ensino e a pesquisa de forma indissociável e viabiliza a relação transformadora entre universidade e a sociedade. A extensão é uma via de mão dupla com trânsito assegurado à comunidade acadêmica, que encontrará na sociedade a oportunidade da elaboração da práxis de um conhecimento acadêmico. No retorno à universidade, docentes e discentes terão um aprendizado que submetido à reflexão teórica, seria acrescido àquele conhecimento. Este fluxo, que estabelece a troca de saberes sistematizados/acadêmico e popular, terá como consequência a mudança de conhecimento acadêmico e a participação efetiva da comunidade na atenção da universidade (FORPROEX, 2001, p. 5).
\end{abstract}

A esse respeito, Silva (1996) salienta que a extensão universitária oferece aos universitários a oportunidade de colocar em prática os conhecimentos adquiridos em sala de aula. A possibilidade de "ensino-aplicação" é uma maneira planejada de preparar seus profissionais com teoria, complementando a formação com estratégias metodológicas.

Ao colaborar com a comunidade local, prestando-lhe serviços que atendam a sua demanda, a Instituição de Ensino Superior é agraciada com ganhos acadêmicos, já que as ações desenvolvidas trazem-lhes conhecimentos relativos à seleção e análise de metodologias mais acertadas para os trabalhos desenvolvidos, a observação e o conhecimento dos problemas reais existentes na vivência comunitária, bem como a experiência profissional para professores e universitários.

Portanto, a extensão universitária apresenta-se como importante instrumento para produção de conhecimento, atento às reais necessidades sociais. Mostra-se, também, como estratégia privilegiada para estimular a aproximação entre a teoria e a prática. Os avanços nesse sentido promovem a universidade no seu sentido nato de compromisso social e cidadão.

\title{
Desenvolvimento do Projeto de Extensão
}

O desenvolvimento do Projeto de Extensão Comunitária de Apoio Escolar às crianças com dificuldade de aprendizagem, aqui apresentado, embasa-se nas concepções de Philippe Meirieu (1998, 2002 e 2005) sobre os conhecimentos docentes e sua formação auto reflexiva.

Pioneiro no curso de Pedagogia da Universidade Paulista, tal projeto vem sendo desenvolvido nas dependências do campus de Araraquara-SP desde o ano de 2009 e atende às crianças semanalmente, aos sábados, das 9 h00 às $11 \mathrm{~h} 00$, no Laboratório de Pedagogia, levadas por uma pessoa de sua família.

Segundo as mães e as professoras, elas apresentam dificuldades na leitura e escrita e problemas de comportamento, tais como agressividade e indisciplina ou timidez, resistência, falta de iniciativa, insegurança e autoestima rebaixada.

Durante os encontros, no processo de acompanhamento e intervenção, buscase estabelecer caminhos e alternativas para cada criança e criar enigmas para instigar a motivação, bem como, elevar sua autoestima.

Os recursos pedagógicos são diversificados e diferenciados daqueles utilizados nas aulas regulares da escola, na tentativa de estimular o interesse e o envolvimento da 
criança e levá-la a se sentir sujeito da construção do conhecimento. Adotando estratégias inovadoras e construtivas, busca-se instigar a criança a construir conceitos cognitivos e atitudinais para atingir o desenvolvimento de habilidades de leitura, escrita e resolução de problemas. Busca-se, também, desenvolver sua autonomia e sua capacidade de aprender, por meio de materiais didáticos, presentes no Laboratório de Brinquedos, confeccionados pelos próprios universitários nas aulas práticas de metodologias de ensino.

São apresentados jogos, brincadeiras, músicas e instrumentos musicais (bandinha), almejando aprendizagem que tenha significado e aplicabilidade em outras situações da vida das crianças. Utiliza-se, também, atividades de jogos educativos no ambiente do laboratório de informática da universidade.

A respeito da pedagogia diferenciada, Meirieu (1998) recorre à ideia de que nem todos aprendem ao mesmo ritmo, de acordo com os mesmos padrões, assimilando da mesma maneira, com a mesma facilidade. Por isso, é necessário estabelecer caminhos e alternativas para cada conjunto de alunos. Não se pode fechar cada um na sua própria estratégia de aprendizagem; devem ser abertas perspectivas e a aprendizagem deve abrir caminhos para a metacognição. O saber não é a soma de técnicas, mas sim o aprender a refletir, a esmiuçar os conteúdos, a pensar para além de.

Durante os encontros, o trabalho em grupo é priorizado, valendo-se do princípio de que a prática coletiva de execução de atividades permite produções mais elaboradas e mais corretas que as exibidas individualmente. Junto ao seu igual, a criança sente-se menos intimidada e mais à vontade para manifestar seu posicionamento e suas dúvidas. Para Meirieu (2005, p. 196), esse tipo de trabalho tem o objetivo de garantir a participação de todos e proporciona a verificação da coletivização das aquisições. "De fato, ele permite variar os métodos, estimular a curiosidade, favorecer as discussões entre as pessoas e atingir objetivos específicos (...)".

Como resultado, o que se tem observado no decorrer destes anos é que, aos poucos, as crianças vão diminuindo sua resistência às atividades e aumentando a participação nelas. Em consequência da mudança de comportamento, atingem melhores resultados na aprendizagem e se mostram satisfeitas em suas realizações, com elevação da autoestima.

A avaliação da criança ocorre por meio de observação de seu desempenho, englobando os aspectos cognitivo, afetivo e social. À medida que realiza suas atividades, ela vai elaborando seu portfólio, traçando o seu percurso e expressando suas realizações, transformações e evoluções, enfim, acompanhando sua evolução na aprendizagem.

Em depoimento coletado na entrevista realizada em novembro de 2014, os pais expuseram sua satisfação com o trabalho desenvolvido, afirmando observar mudança no comportamento do filho em relação às aprendizagens escolares. Segundo eles, o filho passou a se mostrar mais motivado para ir à escola e mais seguro no momento de realizar as tarefas de casa. Disseram, ainda, que o filho demonstra grande interesse em participar dos encontros do Projeto e que relata, com entusiasmo, as brincadeiras e atividades desenvolvidas com os universitários.

Quanto às observações das professoras e da coordenadora da escola, as mesmas dizem perceber mais empenho dos alunos e afirmam ter verificado avanço na aprendizagem de muitos deles.

Para encerramento do ano de trabalho, são realizados encontros de reflexão crítica para avaliar questões relativas ao desenvolvimento do Projeto, tais como, a intervenção 
pedagógica e afetiva e os resultados alcançados pelas crianças. Essa avaliação tem por objetivo verificar se os universitários conseguem relacionar teoria e prática e trabalhar essa relação numa dinâmica de aprender a teoria para compreender a prática, bem como corrigi-la nos pontos deficientes e até descobrir novas aplicações para elas. Nesse aspecto, a intervenção reflexiva sobre a ação pedagógica é considerada pelos estudiosos da área da Educação fator imprescindível para o desenvolvimento pessoal e profissional docente.

\section{Os Universitários}

Neste ano de 2015 participam do desenvolvimento do Projeto de Extensão Comunitária dez universitários do $1^{\circ}, 2^{\circ}$ e $3^{\circ}$ anos, tendo um deles, do $3^{\circ}$ ano, a função de monitor do Projeto.

No que se refere aos encontros dos universitários com a professora-orientadora, responsável pelo Projeto, constata-se interesse deles em se autoavaliar e conhecer a avaliação da professora para poderem redirecionar seus trabalhos. Tal reflexão crítica objetiva relacionar teoria e prática e trabalhar a dinâmica de aprender a teoria para compreender a prática, corrigir os pontos deficientes e até descobrir novas aplicações para suas ações.

A esse respeito, Meirieu (2005, p. 202) considera essencial levar-se em conta orientações e análises de aquisições de uns e de outros, permitindo, assim, que cada um encontre a sua melhor maneira de trabalhar. "E é sempre conveniente que o professor recontextualize regularmente o trabalho e faça um balanço dele, que realize sínteses, formalize as aquisições e indique os objetivos a serem atingidos".

A participação dos universitários implica a realização de duas ordens de atividades. A primeira diz respeito àquelas realizadas com a professora-orientadora, constituídas de elaboração do planejamento dos encontros e dos recursos didáticos; de elaboração de relatório dos encontros; de estudo de textos literários sobre metodologias de ensino; de avaliação do Projeto para revisão e reformulação de ações.

A segunda ordem de atividades refere-se às realizadas diretamente com as crianças, ou seja, a aplicação de avaliação diagnóstica; a elaboração de relatório e análise preliminar dos resultados da avaliação; a elaboração de propostas de atividades, de acordo com os resultados apresentados na avaliação diagnóstica; a observação constante do desempenho da criança na realização das atividades e a elaboração de avaliações para acompanhamento dos avanços e recuos no processo ensino-aprendizagem.

Em atividade de avaliação e reflexão sobre o desenvolvimento do projeto de extensão, os universitários relatam sua capacidade de observar as habilidades e competências das crianças, bem como os interesses e atitudes delas, tanto nos primeiros dias como no decorrer dos encontros. Suas respostas mostram, ainda, percepção de suas próprias ações e capacidade de vislumbrar alternativas de intervenção junto às crianças, dependendo das atitudes positivas ou negativas nas situações vivenciadas.

Vale ressaltar que em discussões com a professora orientadora, dizem-se preocupados quanto às intervenções pedagógicas e afetivas que deverão adotar para ajudar seus alunos quando forem trabalhar na escola e surgirem problemas de aprendizagem ou de comportamento. Acreditam que com os conhecimentos adquiridos no curso de Pedagogia e, em especial, no desenvolvimento deste projeto, terão mais segurança para lidar com os alunos quando, por exemplo, na sala de aula, estes se encontrarem em desentendimentos 
ou lhes fizerem certos questionamentos.

Em relação à preocupação dos universitários, Meirieu (2002, p. 70) defende que para cumprir seu projeto de educar, o professor não pode dispensar as emoções em suas ações e suas principais virtudes devem ser a indignação e a inquietude. Enfatiza a "solicitude pedagógica" que, segundo o autor, é a verdadeira expressão da preocupação consigo e com o outro. Ela "se insere em um fundo de inquietude, beira o tormento, manifesta-se pela preocupação assumida pelo futuro do outro tanto quanto pela vontade de estimulá-lo a agir ele mesmo, a se pôr em movimento e a decidir sua própria trajetória".

Outro ponto importante observado durante os encontros é o cuidado especial dos universitários no trato com as crianças, o que leva ao bom relacionamento entre todos. Orientados, tentam manter um clima de disciplina e organização para trabalhar na sala. No aspecto afetivo, incentivam-nas, conversando, questionando, elogiando ou advertindo de maneira encorajadora, atentos às diferenças de nível de desenvolvimento e de temperamento e à adequação do momento, para não atingir negativamente a autoestima da criança. Em contrapartida, as crianças manifestam carinho por eles, parecem gostar muito deles.

\section{As crianças}

As crianças atendidas no desenvolvimento de tal Projeto têm entre nove e onze anos de idade e são provenientes de quatro escolas públicas do Ensino Fundamental do Ciclo I.

De acordo com a ficha de encaminhamento enviada por seus professores, apresentam dificuldade de aprendizagem e/ou de comportamento.

No que se refere à aprendizagem, segundo seus professores, os alunos apresentam dificuldade na escrita, leitura e interpretação de textos e no raciocínio matemático. E em relação ao de comportamento, problemas como falta de atenção e interação, agressividade, agitação, timidez, imaturidade, preguiça e indisciplina.

$\mathrm{Na}$ avaliação da mãe das crianças, obtida em anamnese, em casa mostram-se agarradas a ela, impacientes, irritadas, agitadas e preguiçosas. No entanto, são obedientes e se relacionam bem com os irmãos.

A respeito dos problemas apresentados por essas crianças, o termo "dificuldades de aprendizagem" destaca a discrepância entre o que se espera que elas sejam capazes de aprender potencialmente e o que elas efetivamente apresentam como aquisições escolares. Tais dificuldades podem ter origem em fatores de ordem pessoal, familiar, pedagógica e social.

Dentro desta abordagem, estudos apontam que a problemática na área afetivosocial e desempenho acadêmico se correlacionam, ou seja, crianças com dificuldade de aprendizagem também apresentam problemas socioemocionais e comportamentais (JACOB; LOUREIRO, 1996; MACHADO; MARTURANO; LOUREIRO; LINHARES; BESSA, 1994).

Weiss (1997, p. 16) considera o fracasso escolar como "uma resposta insuficiente do aluno a uma exigência ou demanda da escola". Essa insuficiência escolar pode estar ligada à ausência de estrutura cognoscitiva, que permite a organização dos estímulos e favorece a aquisição dos conhecimentos. Mas a dificuldade em aprender pode estar 
relacionada a determinantes sociais, da escola e do próprio aluno, ou seja, ligada a fatores internos (cognitivos e emocionais) e a fatores externos, culturais, sociais e políticos (JACOB; LOUREIRO, 1996; WEISS, 1997).

Na perspectiva do fracasso escolar estar relacionado ao aluno, às suas condições internas de aprendizagem, essa perspectiva é, normalmente, considerada pela escola como a causa da maioria dos casos de baixo desempenho escolar, justificada por lares desestruturados, com pais que não acompanham os estudos dos filhos. Segundo Chakur e Ravagnani (2001), a própria criança atribui a si a responsabilidade pelo seu fracasso escolar, julgando-se pouco esforçada nos estudos.

O fato de a criança apresentar dificuldade de aprendizagem não pode ser considerado um problema isolado, de pouca preocupação, já que o fracasso escolar interfere no desenvolvimento afetivo e compromete processos intrapsiquícos relacionados à formação da personalidade da criança, acarretando problemas afetivos, também. Por isso, a necessidade de lhe proporcionar cuidados especiais para sanar ou minimizar tais dificuldades.

\section{Atividades desenvolvidas no ano de 2015}

As propostas de atividades são cuidadosamente planejadas, já que devem se adequar ao nível de desenvolvimento da criança e atender as suas necessidades e aos seus interesses.

Dentre o universo de atividades desenvolvidas, são apresentados jogos e brincadeiras, almejando aprendizagem que tenham significado e aplicabilidade em outras situações da vida das crianças. Utiliza-se, também, atividades de jogos educativos no laboratório de informática da universidade e também de autoavaliação, para que possam desenvolver a capacidade de auto-observação, revisão de metas e mudança de atitudes.

Para este ano de 2015, foi planejado o desenvolvimento do tema "A casa", inspirado no poema de Vinícius de Moraes, no qual se buscou promover o entendimento da casa como:

- estrutura física: composta de cômodos, móveis e utensílios;

- lar: no sentido de moradia, abrigo, local onde se vive e se sente protegido;

- espaço de convivência familiar: relacionamentos, troca afetiva, no qual se sobrepõem emoções, como medo, raiva, alegria, tristeza;

- reconhecimento e valorização dos membros da família.

Sempre em grupos (duplas de crianças e de universitários), algumas atividades já foram trabalhadas no primeiro semestre, sendo que as demais estão sendo desenvolvidas no segundo semestre.

Abaixo, encontram-se cronologicamente elencadas e ilustradas atividades de sete encontros realizados em 2015:

\section{$\mathbf{1}^{\circ}$ encontro:}

- todas juntas, as crianças leem a poesia "A casa";

- tocando os instrumentos musicais da "bandinha"; cantam, acompanhando a letra e a melodia; 
- em duplas, desenham uma casa "engraçada" e escrevem: "o que há de engraçado na casa".

Figura 1- atividades referentes à "casa engraçada"
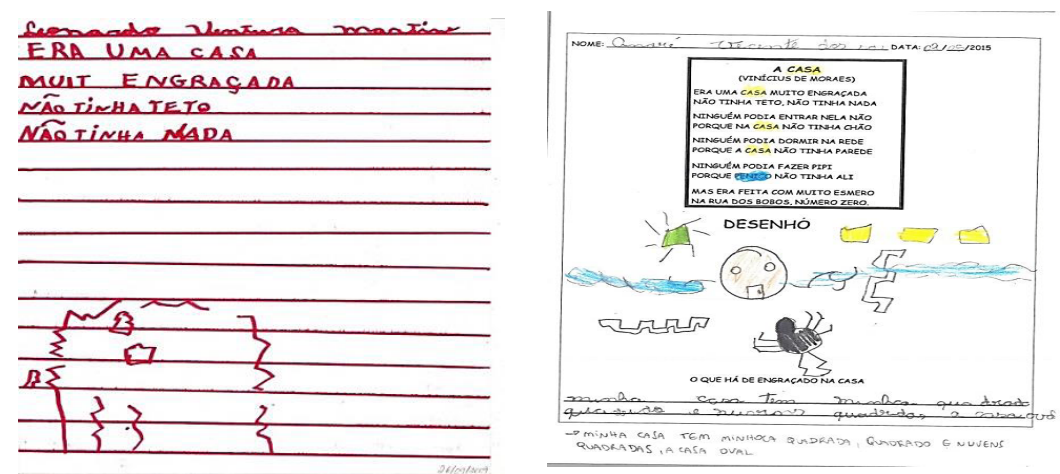

Fonte: Os autores.

\section{$2^{\circ}$ encontro:}

- todas juntas, as crianças recebem a atividade anterior, a poesia "A Casa", e cantam, acompanhando a letra da música;

- trabalhando a estrutura da poesia, cada grupo recebe desordenadamente uma estrofe e faz a reordenação dos versos, que são afixados na lousa;

- fazem a releitura da poesia.

Figura 2- atividades referentes à "estrutura da poesia"
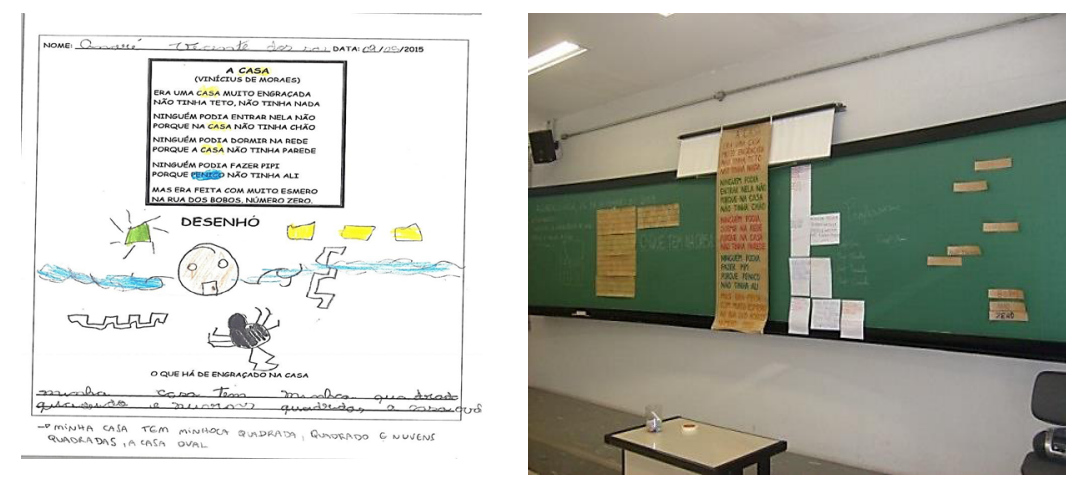

Fonte: Os autores.

\section{$3^{\circ}$ encontro:}

- em duplas, as crianças recebem a atividade da poesia "A Casa" e a leem, novamente;

- a partir do conceito de planta-baixa, descrevem os cômodos de sua casa e apontam seu cômodo preferido;

- desenham os cômodos e a frente da sua casa;

- escrevem: "qual parte da casa que mais gosta?".

Figura 3- atividades referentes aos "cômodos da casa" 

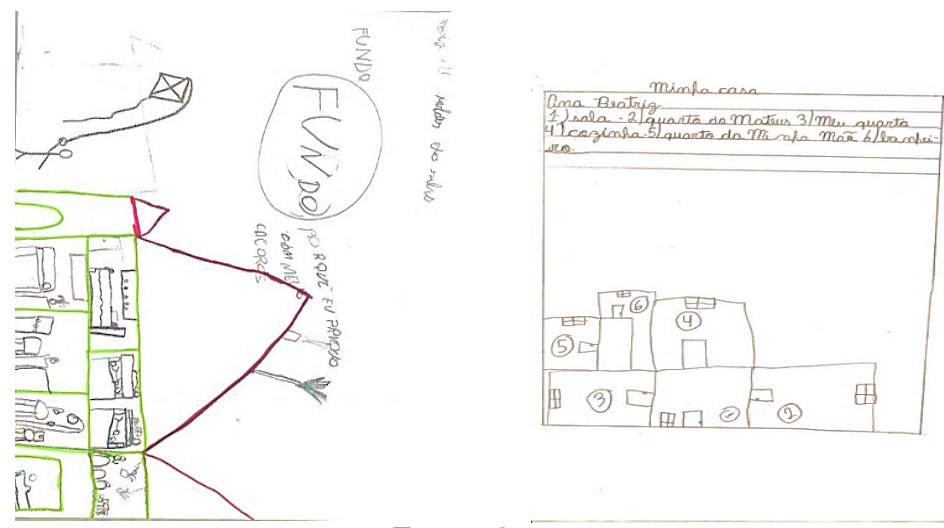

Fonte: Os autores.

\section{$4^{\circ}$ encontro:}

- trabalhando em duplas, as crianças recebem a atividade da poesia "A Casa" e a releem; - oralmente, descrevem os móveis e alguns utensílios de cada cômodo;

- brincam com o jogo da memória, constituído de figuras e palavras de móveis e objetos da casa;

- escrevem algumas palavras contidas no jogo e com elas elaboram frases.

Figura 4- atividades referentes aos "móveis e utensílios da casa"

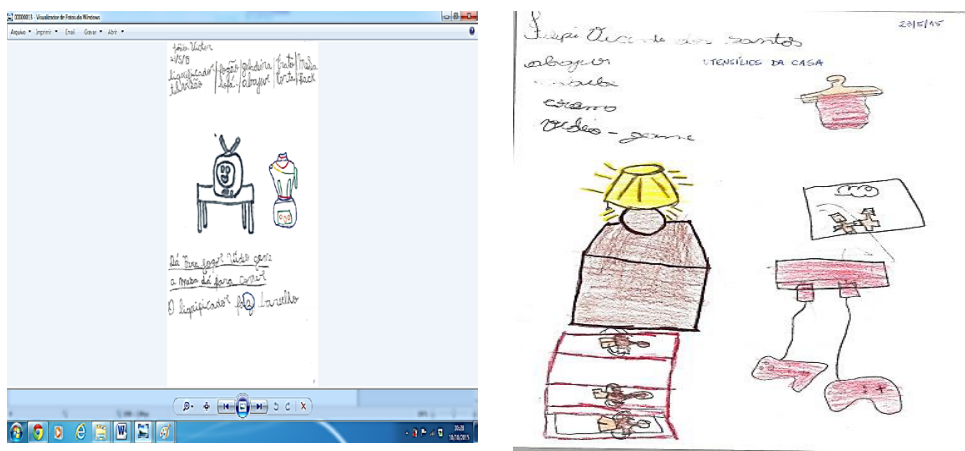

Fonte: Os autores.

\section{$5^{\circ}$ encontro:}

- em duplas, as crianças brincam novamente com o jogo da memória, constituído de desenhos e palavras de móveis e objetos da casa;

- escrevem algumas palavras contidas no jogo e as classificam quanto ao número de sílabas (monossílaba, dissílaba, trissílaba e polissílaba);

- distribuem-nas nos quadros, de acordo com números de sílabas;

- escrevem as famílias silábicas de algumas dessas palavras;

- escrevem outras palavras a partir das referidas sílabas.

Figura 5- atividades referentes aos "móveis e utensílios da casa" 


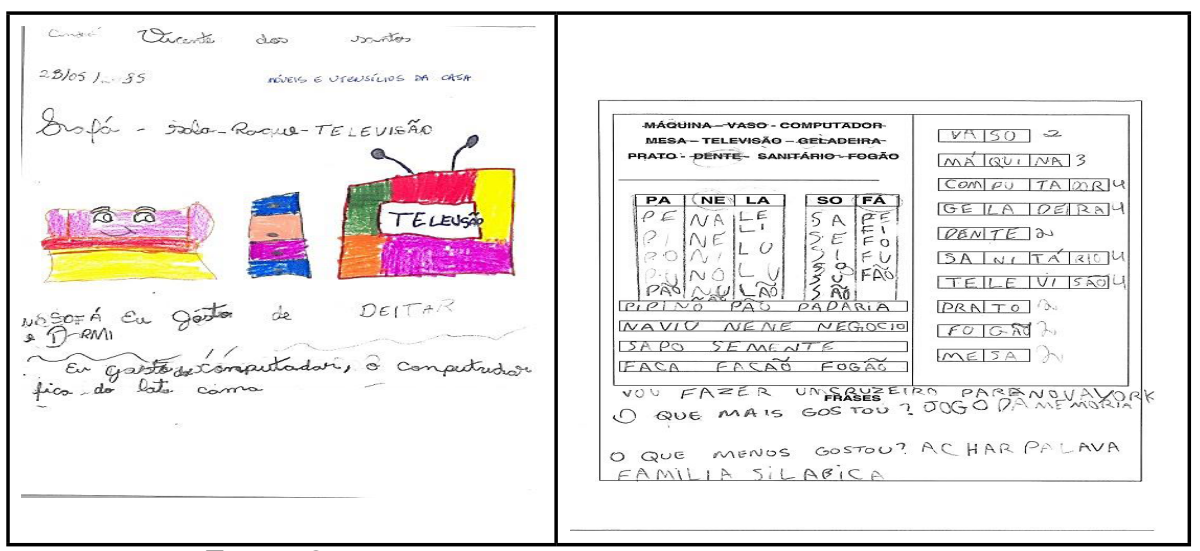

Fonte: Os autores.

\section{$6^{0}$ encontro:}

- trabalhando em dupla, as crianças dão continuidade ao tema "casa e família";

- fazem a leitura da poesia "Lá em casa", destacando os substantivos e adjetivos;

- a partir do jogo "descrevendo aspectos comportamentais", atribuem adjetivos às pessoas de sua casa;

- oralmente, e utilizando as fichas ALEGRE, NERVOSA, CORAJOSA, PACIENTE, CAPRICHOSA, CALMA, CARINHOSA, TRABALHADEIRA, DEDICADA, PREOCUPADA, ENGRAÇADA e SIMPÁTICA, as crianças elaboram frases com três ou mais adjetivos dessas pessoas.

Figura 6- atividades referentes aos "membros da família"

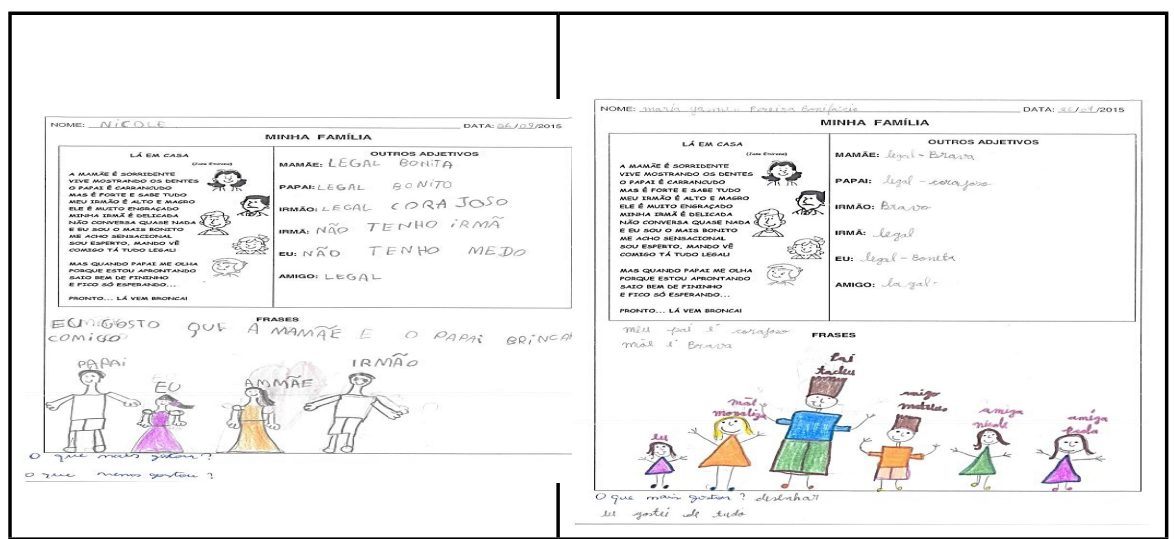

Fonte: Os autores.

\section{$7^{0}$ encontro:}

- todas juntas, as crianças revisam o conceito de substantivo, trabalhando agora o tema "convivência familiar e afetividade - animais de estimação";

- a partir do jogo de bingo "nome de animais", dizem frases com as palavras do bingo;

- em duplas, desenham e escrevem o nome de animais de estimação e completam as frases com as palavras do quadro;

- para finalizar brincam de "forca". 
Figura 7 - atividades referentes à "convivência familiar e afetividade"

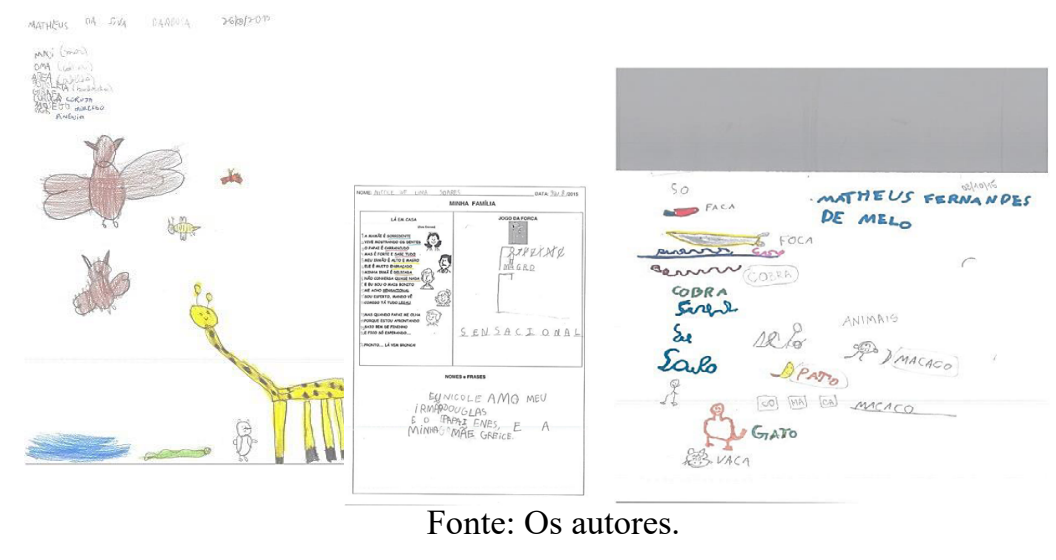

Assim, ao abordar situações do contexto familiar, as atividades buscam instigar o interesse e a participação das crianças e as envolver em reflexão e formulação de respostas que, na maior parte das vezes, têm efeito construtivo ao seu desenvolvimento.

Para Meirieu (2002), a pedagogia das situações-problema pode responder aos desafios da prática de ensinar, desempenhando o que chama de "função erótica", por transcrever o enigma gerador do desejo de saber; de "função didática", que permite a apropriação do conhecimento resultado e de "função emancipadora", na qual o aluno torna-se capaz de resolver seus problemas.

Considerando a relevância da gerência da aprendizagem, Meirieu (1998, p. 80) coloca o "triângulo pedagógico", que é "composto pelo educando, o saber e o educador". Para melhor compreender essa estrutura, defende na atividade pedagógica os três polos do triângulo: $1^{\circ}$ Polo: Educando; $2^{\circ}$ Polo: Saber; $3^{\circ}$ Polo: Educador. Quando a atividade pedagógica reduz sua ação a um único polo, o vínculo entre eles se quebra e se instala o desequilíbrio.

Segundo o autor, se as atividades e os agrupamentos forem bem planejados, os alunos também aprenderão muito uns com os outros, em nível escolar e social, pois é essencial que as habilidades interpessoais e sociais sejam ensinadas, desenvolvidas como parte de qualquer experiência de aprendizagem cooperativa. Uma vez que as habilidades sociais tornam-se internalizadas, elas permitem as crianças trabalharem efetivamente com os outros, ao mesmo tempo em que melhoram seu aproveitamento escolar e desenvolvem importantes habilidades para a vida toda.

Nesse aspecto, defende a utilização de diferentes caminhos metodológicos para se alcançar o objetivo comum de todos os alunos, quais sejam, o de aprender e ter acesso ao desenvolvimento de capacidades de trabalhar com eficiência e pensar com autonomia. Deve-se "levar em conta as aquisições de uns e de outros, reconhecer que existem métodos que funcionam melhor para alguns e que cada um deve encontrar a maneira de trabalhar mais adequada para si próprio" (MEIRIEU, 1998, p. 202).

E porque aprender é difícil e é sempre necessário correr certos riscos e se aventurar por caminhos jamais percorridos, Meirieu (2005, p. 168 e 169) ressalta que, como "nenhuma aprendizagem é garantida a priori e o fracasso - mesmo para um 'bom aluno' é sempre uma possibilidade", o professor tem a responsabilidade de acompanhar o esforço 
de cada um para aprender, na medida em que as "tentativas não sejam estigmatizadas, que os erros sejam vistos como positivos e que os fracassos sejam apresentados como superáveis".

Segundo o autor, no contexto de realização das atividades, as posturas mentais exigidas são determinadas a partir do trabalho estabelecido, já que o aluno desenvolve diferentes atividades mentais, conforme a natureza do trabalho que lhe é solicitado, para investir-se nas possibilidades de compreensão para se apropriar do conhecimento. Por isso, é importante o professor "sempre conceber seu ensino em função do que o aluno deve aprender e compreender. A partir de então, ele pode trabalhar sobre um par essencial, que estrutura a postura mental, o par "encontrar/procurar'" (MEIRIEU, 2005, p. 176).

Neste aspecto, o autor salienta que a aprendizagem somente pode ser confirmada quando o aluno mostra-se capaz de descentralizá-la e recontextualizá-la, transferindo-a na resolução de outra situação de sua vida.

\section{Considerações finais}

Analisando-se a atuação dos universitários para ajudar as crianças no enfrentamento de suas dificuldades, suas intervenções podem ser classificadas em pedagógica e afetiva. Pedagogicamente, estão direcionadas às particularidades pontuais de dificuldade de aprendizagem, que compreendem atividades diferenciadas, sob os mais variados recursos oferecidos a elas.

No aspecto afetivo, os universitários voltam-se à motivação e ao incentivo das crianças, com conversas, questionamentos, elogios ou advertências de maneira encorajadora, atentos às diferenças de nível de desenvolvimento e de temperamento e à adequação do momento, para não atingir negativamente a autoestima da criança.

Pode-se considerar que quando as crianças vivenciam atividades prazerosas e desafiadoras, que dão vontade de aprender, fascinam-nas e as envolvem, sem dúvida sua reação é positiva frente à intervenção que recebem. Ao contrário de situações que estabelecem clima de ameaça e punição para os desinteressados pelas atividades e geram respostas desde as mais conformistas até as mais indisciplinadas.

Mas qual é o professor que se encontra, realmente, em condições favoráveis de observar seus alunos, avaliar suas capacidades, reconhecer suas dificuldades e intervir eficazmente, buscando e encontrando metodologias adequadas às particularidades de cada um? Qual é o professor que questionará suas ações e refletirá sobre elas, de maneira crítica?

Mais uma vez, recorre-se às ideias de Meirieu (2005), ao referir-se que somente o professor com boa formação e comprometido com suas responsabilidades tornar-se-á capaz de se perceber e perceber seus saberes e seus alunos, para bem orientá-los e lhes oferecer instrumentos adequados às suas necessidades.

\section{Referências}

BRASIL. Conselho Nacional de Educação. Conselho Pleno. Resolução $\mathrm{CNE} / \mathrm{CP} \mathrm{n}^{\circ} 1$, de 15 de maio de 2006. Institui Diretrizes Curriculares Nacionais para o Curso de Graduação em Pedagogia, licenciatura. Brasília: SEED, 2006.

BRASIL. Conselho Nacional de Educação. Parecer CNE/CP n ${ }^{\circ}$ 5, de 13 de dezembro 
de 2005. Institui Diretrizes Curriculares Nacionais para o Curso de Graduação em Pedagogia. Brasília: SEED, 2005.

CHAKUR, C. R. S. L. A profissionalidade docente em uma abordagem construtivista. In: Cadernos de Pesquisa - Revista de Estudos e Pesquisas em Educação, no ${ }^{\circ} 117$, p. 149-176, nov. 2002.

CRUZ, S. A. B. Aprender pela escola à luz de Meirieu: experiência de formação de professores em meio à sala de aula. 2011. 248m f. Tese (Doutorado em Educação) Faculdade de Ciências e Letras, Universidade Estadual Paulista Júlio de Mesquita Filho, Araraquara, 2011.

CRUZ, S. A. B. O professor diante das dificuldades de aprendizagem dos seus alunos: concepções e intervenções. 2003. Dissertação (Mestrado em Educação) Faculdade de Ciências e Letras, Universidade Estadual Paulista Júlio de Mesquita Filho, Araraquara, 2003.

FÓRUM DE PRÓ-REITORES DE EXTENSÃO DAS UNIVERSIDADES PÚBLICAS BRASILEIRAS. Política Nacional de Extensão Universitária. Manaus: Forproex, 2012. Disponível em: <http://www.renex.org.br/documentos/2012-07-13-Politica-NacionaldeExtensao.pdf. $>$. Acesso em: 10 out. 2015.

FÓRUM DE PRÓ-REITORES DE EXTENSÃO DAS UNIVERSIDADES PÚBLICAS BRASILEIRAS. Plano Nacional de Extensão (1999-2001). Brasília. SESU/MEC, 2001. IAMAMOTO, M. V. Reforma do Ensino Superior e Serviço Social. In: Revista da Associação Brasileira de Ensino e Pesquisa em Serviço Social (Abepss). Brasília: Valci, 2000.

IMBERNÓN, F. Formação Docente e Profissional: formar-se para a mudança e a incerteza. São Paulo: Cortez, 2006.

JACOB, A.V.; LOUREIRO, S. R. Desenvolvimento afetivo - o processo de aprendizagem e o atraso escolar. In: Paidéia, FFCLRP-USP, Ribeirão Preto, fev/ago. 1996.

MACHADO, V. L. S. et al. Crianças com dificuldades na aprendizagem escolar: características de comportamento conforme avaliação de pais e professores. In: Arquivos brasileiros de Psicologia, 46 (3/4), 119-138, 1994.

MELLO, G. N. Formação inicial de professores para a educação básica: uma (re)visão radical. In Revista Iberoamericana de Educación, Madrid / Buenos Aires, $n^{\circ}$ 25, 2001, pp. 147-174. 
MEIRIEU, P. O quotidiano da escola e da sala de aula. Porto Alegre: Artmed, 2005.

A Pedagogia entre o Dizer e o Fazer. Porto Alegre: Artmed, 2002.

. Aprender sim, ...mas como? Porto Alegre: Artmed, 1998.

SILVA, O. D. O que é extensão universitária? Disponível em: $<$ http://www. ecientificocultural.com/ECC2/artigos/oberdan9.html>. Acesso em: 1 set. 2008.

WEISS, M. L. L. Psicopedagogia clínica: uma visão diagnóstica dos problemas de aprendizagem escolar. Rio de Janeiro: DP \& A. 1997 